\title{
Deflection of carbon dioxide laser and helium-neon laser beams in a long-pulse relativistic electron beam diode
}

\author{
R. A. Bosch, H. Ching, R. M. Gilgenbach, P. L. G. Ventzek, \\ P. R. Menge, J. J. Choi, and T. A. Spencer \\ Intense Energy Beam Interaction Laboratory, Nuclear Engineering Department, \\ The University of Michigan, Ann Arbor, Michigan 48109-2104
}

(Received 4 February 1991; accepted for publication 15 March 1991)

\begin{abstract}
Deflection of carbon dioxide and helium-neon laser beams has been used to measure plasma and neutral density gradients during the operating mode and after the shorting time of a long-pulse field-emission electron beam diode. Plasma density gradients of $\left(10^{14}-10^{15}\right)$ $\mathrm{cm}^{-4}$ were observed throughout the diode during the final microsecond of the $2-3 \mu \mathrm{s}$ electron beam pulse. The neutral density gradient was less than $1 \times 10^{18} \mathrm{~cm}^{-4}$ during the electron beam pulse. Upon diode shorting, neutral density gradients increased to $\left(10^{18}-\right.$ $10^{19}$ ) $\mathrm{cm}^{-4}$ over $\sim 1 \mu \mathrm{s}$, and decayed over many microseconds. Plasma density gradients of $\sim 10^{15} \mathrm{~cm}^{-4}$ were also observed after shorting. These experiments demonstrate the value of carbon-dioxide laser and helium-neon laser defiection for diagnosing plasma and neutral particles in long-pulse electron beam diodes.
\end{abstract}

\section{INTRODUCTION}

Field-emission electron beam diodes can be used to provide long-pulse electron beams with energies of $\sim 1$ $\mathrm{MeV}$, pulse length $\sim 1 \mu \mathrm{s}$, and multikiloampere currents. ${ }^{1}$ In a typical diode, an electric field of hundreds of kilovolts per centimeter is applied between parallel plates separated by a few centimeters. The cathode may be covered with felt or velvet to provide electric field enhancement at the tips of fibers. The application of the electric field initiates a series of events: (1) cathode turn-on in which plasma spots form on the cathode and coalesce into a plasma layer over several ns, providing an electron source; (2) operating mode, a time period on the order of $2 \mu$ s (for anode-cathode gaps of several $\mathrm{cm}$ ) during which electrons from the cathode plasma are accelerated towards the anode at energies $\sim 1$ $\mathrm{MeV}$, and the diode impedance drops towards zero; and (3) shorting, a high-current, low-impedance arc with decreased voltage between anode and cathode, during which the diode becomes filled with neutral particles and plasma.

The diode impedance during the operating mode is typically that of a vacuum diode whose anode-cathode separation decreases linearly with time at a velocity of several $\mathrm{cm} / \mu$ s. Researchers have frequently relied upon the timedependent diode impedance to infer the diode properties. ${ }^{2}$ The impedance behavior has been ascribed to the diode filling with cathode plasma (the expansion of the cathode plasma created during turn-on plus additional production), in which the boundary of the plasma-filled region moves from cathode to anode at a uniform velocity. For sufficiently high energy deposition in the anode by the accelerated electrons, anode plasma is also formed. ${ }^{3.4}$

Cathode plasma and cathode neutrals have been previously observed with optical interferometry using a nitrogen laser at $\lambda=0.3371 \mu \mathrm{m}$ in a relativistic electron beam diode with anode-cathode gap of $2.4 \mathrm{~mm}$ and $100 \mathrm{~ns}$ pulse length. ${ }^{5}$ In a diode with $1.5 \mathrm{~mm}$ gap and $35 \mathrm{~ns}$ pulse length, the energy deposition in the anode by accelerated electrons was sufficient to create an anode plasma that was observed in addition to cathode plasma by visible interferometry using a ruby laser at $\lambda=0.6943 \mu \mathrm{m}$. ${ }^{4}$ Cathode and anode plasmas were observed with ruby laser interferometry in a relativistic electron beam diode ${ }^{6}$ and a magnetically insulated ion diode ${ }^{7}$ with anode-cathode gaps of $5 \mathrm{~mm}$. Deflection of a helium-neon laser $(\lambda=0.6328 \mu \mathrm{m})$ by cathode plasma density gradients has been previously observed with a 1.2-cm-diam cathode in the long-pulse diode of the present experiment at the University of Michigan. ${ }^{8}$

Sensitivity to plasma has been one limitation of visible light probing techniques. Sensitivity has been insufficient to observe plasma densities less than $\sim 1 \times 10^{16} \mathrm{~cm}^{-3}$, limiting observation of plasma to the regions within a few $\mathrm{mm}$ of the cathode or anode. In addition, the contributions of plasma and neutrals to the measured refractive index cannot be separated with a single wavelength measurement when both species are present. This limitation is important after the diode shorts.

In this article, we describe two-wavelength deflection measurements using carbon dioxide $\left(\mathrm{CO}_{2}\right)$ and heliumneon ( $\mathrm{He}-\mathrm{Ne}$ ) lasers traversing nearly identical paths through a planar diode with anode-cathode separation of 8 cm. The $\mathrm{CO}_{2}$ laser deflection from plasma density gradients is 280 times as great as that of the He-Ne laser because of its longer wavelength $(10.6 \mu \mathrm{m}$ as opposed to 0.633 $\mu \mathrm{m})$, while the deflection from neutral gradients are nearly the same (within $3 \%$ ). As a result, increased sensitivity to plasma density gradients is provided by the $\mathrm{CO}_{2}$ laser, allowing observation of plasma throughout the diode. From the knowledge of the deflection of both $\mathrm{CO}_{2}$ and $\mathrm{He}-\mathrm{Ne}$ lasers at the same time and location, both the plasma and neutral density gradients may be deduced. With this additional capability, density gradients after the shorting time, when both neutral and plasma species are present, have been determined.

With laser beams skimming the cathode, a cathode plasma density gradient was observed during the final $\mu$ s of 
the 2-3 $\mu$ s electron beam pulse, peaking at $\sim 1.5 \times 10^{15}$ $\mathrm{cm}^{-4}$ near shorting time. The neutral density gradient was less than $1 \times 10^{18} \mathrm{~cm}^{-4}$ during this time period. Upon shorting, a neutral density gradient indicative of cathodeproduced neutrals was observed near the cathode, increasing to $6 \times 10^{18} \mathrm{~cm}^{-4}$ over $\sim 1 \mu \mathrm{s}$, and decaying over many microseconds. The cathode plasma density gradient reverses direction at shorting time and disappears over the following $\mu \mathrm{s}$, consistent with the cathode plasma being pushed away from the cathode by the expanding neutral cloud. Several $\mu$ s later, plasma density gradients of several $10^{14} \mathrm{~cm}^{-4}$ appear, with density increasing away from the cathode.

Cathode plasma density gradients of $\sim 1 \times 10^{14} \mathrm{~cm}^{-4}$ prior to shorting were observed with $\mathrm{CO}_{2}$ laser deflection at distances of 1.5 and $4.5 \mathrm{~cm}$ from the cathode. With the $\mathrm{CO}_{2}$ laser skimming the anode, a plasma density gradient of $2 \times 10^{14} \mathrm{~cm}^{-4}$ increasing towards the anode was observed during the final $0.5 \mu$ s preceding shorting.

\section{APPARATUS}

This experiment was performed using the Michigan Electron Long Beam Accelerator (MELBA), operated with parameters of peak voltage $=-900 \mathrm{kV}$, peak diode current of $50 \mathrm{kA}$, and pulse length of $\sim 2 \mu \mathrm{s}$. This accelerator consists of a modified Marx generator, in which the voltage is compensated by a reverse-charged resistance-inductance-capacitance (RLC) ringing circuit. ${ }^{9}$ The cold cathode was an aluminum disk of $10 \mathrm{~cm}$ diameter covered with carbon felt, separated from the carbon anode plate by a distance of $8 \mathrm{~cm}$. A shielded guard ring $(0 . d .=14 \mathrm{~cm}$ ) covers the edge of the fabric cathode, exposing $7.6 \mathrm{~cm}$ diameter of fabric. A current density of $30-125 \mathrm{~A} / \mathrm{cm}^{2}$ was thereby produced. Voltage was measured with a resistive divider, while anode current was measured with wide-band current transformers (Pearson Electronics 110A) on four isolated current return paths.

A schematic of the experiment is shown in Fig. 1. A 5 $\mathrm{mW}$ He-Ne laser is directed through the diode, upon a 10.8 $\mathrm{m}$ path into a Faraday cage, through a He-Ne line filter, to a photodiode quadrant detector (Silicon Detector Corporation SD-380-23-21-051) with a very fast differential amplifier. ${ }^{10}$ With the resultant laser spot size $(\sim 1 \mathrm{~cm})$, the detector output is proportional to the laser spot position over a distance of $\sim 1 \mathrm{~cm}$, so that deflections up to \pm 0.5 mrad can be measured.

A 1-5 $\mathrm{W} \mathrm{CO}_{2}$ laser provides a $7 \mathrm{~mm}$ beam for infrared laser deflection. The beam traverses $6 \mathrm{~m}$, then is reduced and focused using a $\mathrm{NaCl}$ lens pair $2 \mathrm{~m}$ from the diode, with best focus in the diode. This provides a beam diameter of $\sim 5 \mathrm{~mm}$ on its $7.6 \mathrm{~cm}$ path through the diode, which is nearly identical to the $\mathrm{He}-\mathrm{Ne}$ path in the diode. Because of diffraction effects, the $\mathrm{CO}_{2}$ beam diameter cannot be significantly reduced over a $7.6 \mathrm{~cm}$ path length. The beam is then directed on a $11.3 \mathrm{~m}$ path to the Faraday cage, and focused onto a detector using a $\mathrm{NaCl}$ lens with $10 \mathrm{~cm}$ focal length. A knife edge bisects the beam (diam $\sim 4 \mathrm{~cm}$ ) as it exits this final lens. The detector used was a liquid-nitrogen-cooled Raytheon IR101 PbSnTe detector with Ray- theon DA-20 preamplifier (bandwidth of $20 \mathrm{~Hz}$ to 4 $\mathrm{MHz}$ ), filtered with a $10.6 \mu \mathrm{m}$ line filter. The portion of the beam intersected by the knife edge changes with the laser spot position, so that the detector signal varies linearly with laser spot position over a distance of $\sim 2 \mathrm{~cm}$. Deflections up to $\pm 1 \mathrm{mrad}$ can thus be measured.

Response curves of the $\mathrm{CO}_{2}$ and $\mathrm{He}-\mathrm{Ne}$ laser deflection systems are shown in Fig. 2. A position shift of $1 \mathrm{~cm}$ over the $10 \mathrm{~m}$ path from the diode to the detectors corresponds to a deflection of $1 \mathrm{mrad}$. Deflection signals were converted from $\mathrm{mV}$ to mrad using the slope of these curves at the initial laser spot position. Because the $\mathrm{CO}_{2}$ laser power varied from shot to shot, the curve in Fig. 2(a) was normalized to the laser power for each shot. Electrical noise upon the deflection signals was monitored during each data run by performing shots with the laser paths blocked.

\section{THEORY}

Laser deflection results from plasma and neutral density gradients $\left(d n_{e} / d z\right.$ and $\left.d n_{n} / d z\right)$ in the diode according to:

$$
\theta=-L \frac{d \eta}{d z}=-L\left(K_{e} \frac{d n_{e}}{d z}+K_{n} \frac{d n_{n}}{d z}\right)
$$

where $\theta$ is the deflection angle in radians, $L$ is the path length through the diode $(7.6 \mathrm{~cm}), z$ is the distance from the cathode to the laser path, $\eta$ is the refractivity of the medium in the diode, $K_{e}$ is the Gladstone-Dale constant for plasma electrons (in $\mathrm{cm}^{3} /$ electron), and $K_{n}$ is the Gladstone-Dale constant for neutrals (in $\mathrm{cm}^{3} /$ atom). $K_{e}$ and $K_{n}$ have opposite signs, so that the laser is deflected in opposite directions by plasma and neutral density gradients. A deflection towards the cathode is positive.

$K_{e}$ equals $-\left(2 n_{c}\right)^{-1}$, where $n_{c}$ is the critical plasma density for the laser wavelength. $K_{e}$ depends upon the laser wavelength as $\lambda^{2} ; K_{n}$ depends upon the neutral species composition, but has little dependence upon laser wavelength. $K_{e}=-5.0 \times 10^{-20} \mathrm{~cm}^{3} /$ electron for the $\mathrm{CO}_{2}$ laser beam $(\lambda=10.6 \mu \mathrm{m})$, while $K_{e}=-1.8 \times 10^{-22}$ $\mathrm{cm}^{3} /$ electron for the He-Ne laser beam $(\lambda=0.633 \mu \mathrm{m}) .^{10}$ Thus, the $\mathrm{CO}_{2}$ laser deflection is 280 times as sensitive to plasma electrons. For neutral carbon atoms, $K_{n}=6.25$ $\times 10^{-24} \mathrm{~cm}^{3} /$ atom for the $\mathrm{CO}_{2}$ laser and $6.4 \times 10^{-24}$ $\mathrm{cm}^{3} /$ atom for the He-Ne laser, ${ }^{11}$ a difference of only $3 \%$. A summary of the laser defiection parameters is given in $\mathrm{Ta}$ ble I.

From Eq. (1), we can write:

$$
\begin{aligned}
\theta_{\mathrm{CO}_{2}}= & (7.6 \mathrm{~cm})\left(\left(5.0 \times 10^{-20} \mathrm{~cm}^{3}\right) \frac{d n_{e}}{d z}\right. \\
& \left.-\left(6.25 \times 10^{-24} \mathrm{~cm}^{3}\right) \frac{d n_{n}}{d z}\right), \\
\theta_{\mathrm{HeNe}}= & (7.6 \mathrm{~cm})\left(\left(1.8 \times 10^{-22} \mathrm{~cm}^{3}\right) \frac{d n_{e}}{d z}\right. \\
& \left.-\left(6.4 \times 10^{-24} \mathrm{~cm}^{3}\right) \frac{d n_{n}}{d z}\right) .
\end{aligned}
$$




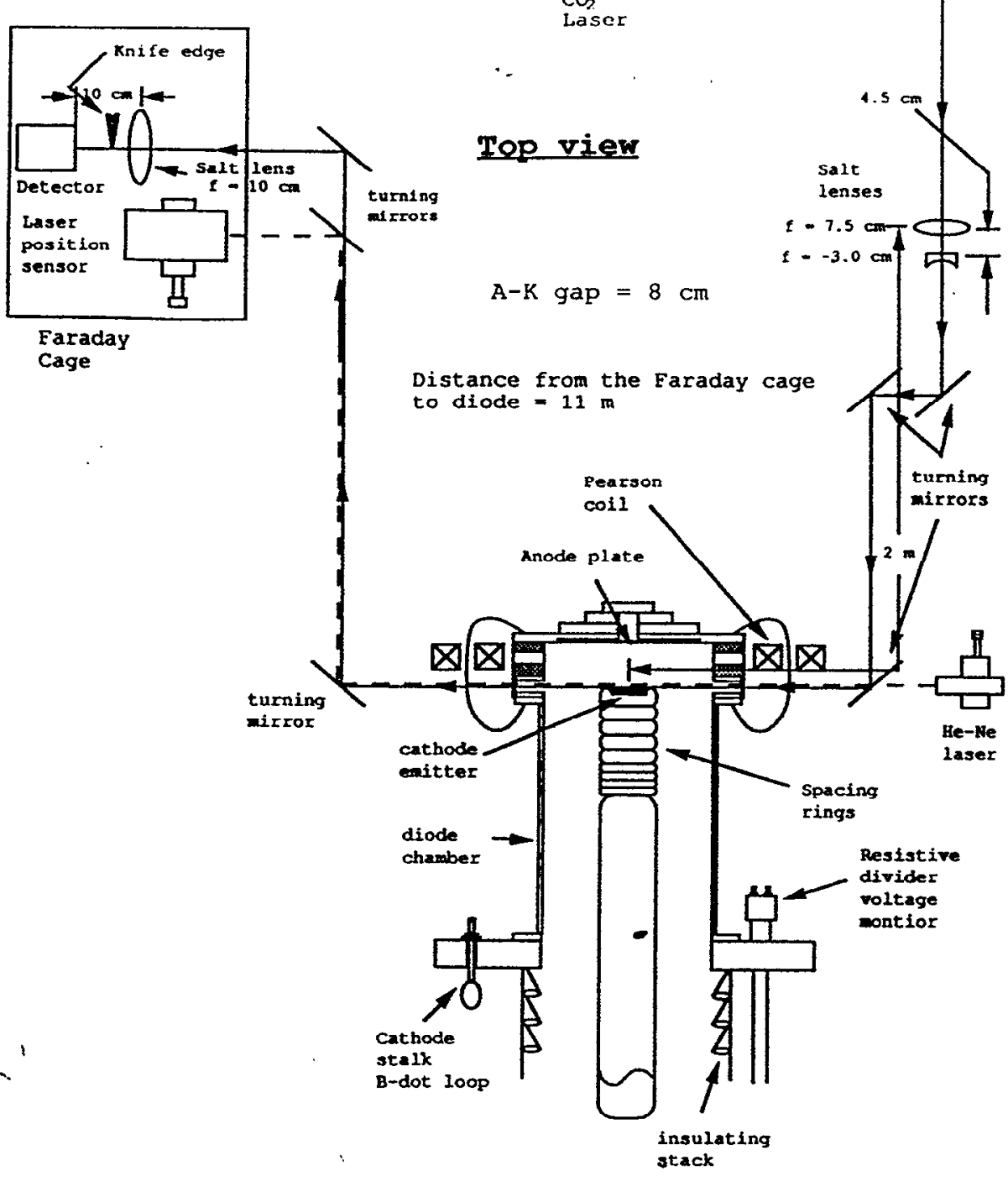

FIG. 1. Experimental configuration.

Multiplying Eq. (3) by 0.97 and subtracting it from Eq. (2) yields:

$$
\begin{aligned}
\theta_{\mathrm{CO}_{2}} & -(0.97) \theta_{\mathrm{HeNe}} \\
& =(7.6 \mathrm{~cm})\left(\left(5.0 \times 10^{-20} \mathrm{~cm}^{3}\right) \frac{d n_{e}}{d z}\right) .
\end{aligned}
$$

Equation (4) allows the plasma density gradient to be determined from the measured deflections. Similarly,

$$
\begin{aligned}
\theta_{\mathrm{HeNe}} & -(0.0036) \theta_{\mathrm{CO}_{2}} \\
= & (7.6 \mathrm{~cm})\left(-\left(6.4 \times 10^{-24} \mathrm{~cm}^{3}\right) \frac{d n_{n}}{d z}\right) .
\end{aligned}
$$

For $\mathrm{CO}_{2}$ and $\mathrm{HeNe}$ deflection angles of the same order of magnitude, the $\mathrm{CO}_{2}$ contribution to Eq. (5) is negligible, so that the HeNe laser deflection may be attributed to neutral density gradients. This is the case in our results. The $\mathrm{CO}_{2}$ deflection minus 0.97 times the HeNe deflection is proportional to the plasma density gradient. Prior to diode shorting, the He-Ne deflection was not observable, so that the $\mathrm{CO}_{2}$ deflection is proportional to the plasma density gradient.

\section{RESULTS}

Observations with $\mathrm{He}-\mathrm{Ne}$ and $\mathrm{CO}_{2}$ laser beams simultaneously skimming the cathode have shown deflection angles of the same order of magnitude for both lasers. This indicates that the observed He-Ne deflection results from the neutral density gradient. In Fig. 3, we display data for laser beams skimming the cathode. The He-Ne deflection is not observable during the operating mode of the diode, indicating that the neutral density gradient is less than $1 \times 10^{18} \mathrm{~cm}^{-4}$. Upon shorting, cathode-produced neutrals produce a density gradient of carbon atoms building to $6 \times 10^{18} \mathrm{~cm}^{-4}$ over $\sim 1 \mu \mathrm{s}$, and decreasing over several microseconds. Similar He-Ne deflection signals were ob- 

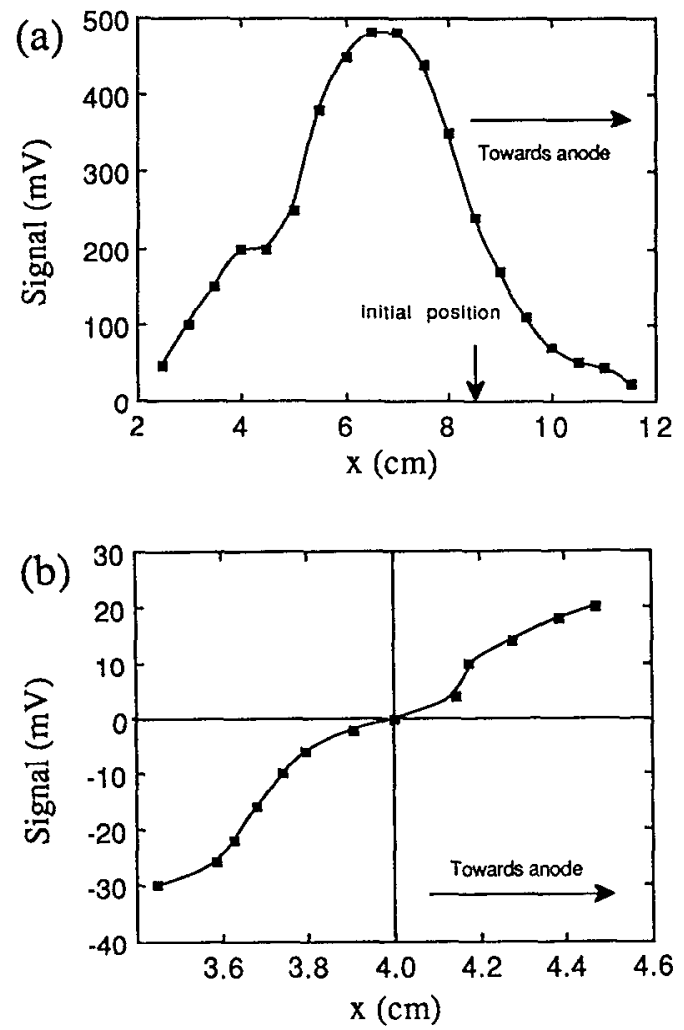

FIG. 2. Calibration curves for laser deffection systems: (a) $\mathrm{CO}_{2}$ laser calibration curve. (b) He-Ne laser calibration curve.

served in other locations near the cathode. When the $\mathrm{He}-\mathrm{Ne}$ laser skimmed the anode, the deflection signal was similar but inverted, consistent with anode-produced neutrals.

Subtracting the neutral-produced $\mathrm{He}-\mathrm{Ne}$ deflection from the $\mathrm{CO}_{2}$ deflection signal yields the plasma-produced deflection, shown in Fig. 3(e). This is a bipolar signal indicating a cathode-plasma density gradient building to $\sim 1.5 \times 10^{15} \mathrm{~cm}^{-4}$ during the final microsecond of the operating mode. The deflection reverses direction at shorting time and builds to a comparable angle in the opposite direction, indicating that plasma density increases away from the cathode. This is consistent with the cathode plasma being pushed away by cathode-produced neutrals after the shorting time. A plasma density gradient of $5 \times 10^{14}$ $\mathrm{cm}^{-4}$ increasing away from the cathode is observed $4 \mu \mathrm{s}$ (a)

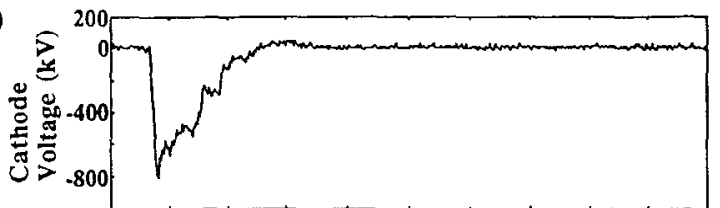

(b)

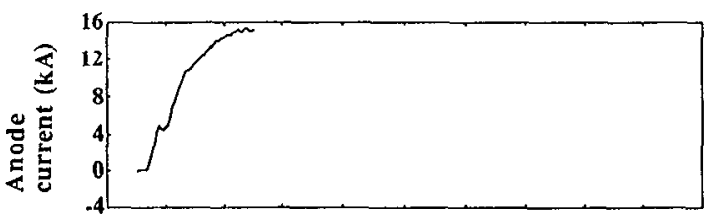

(c)

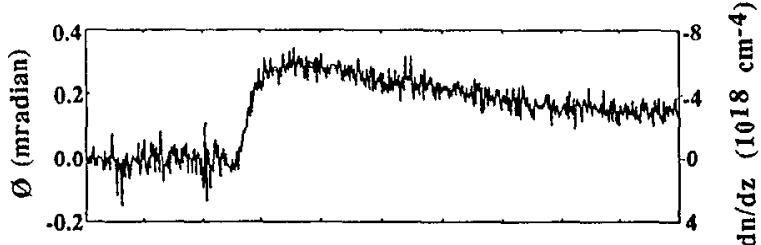

(d)
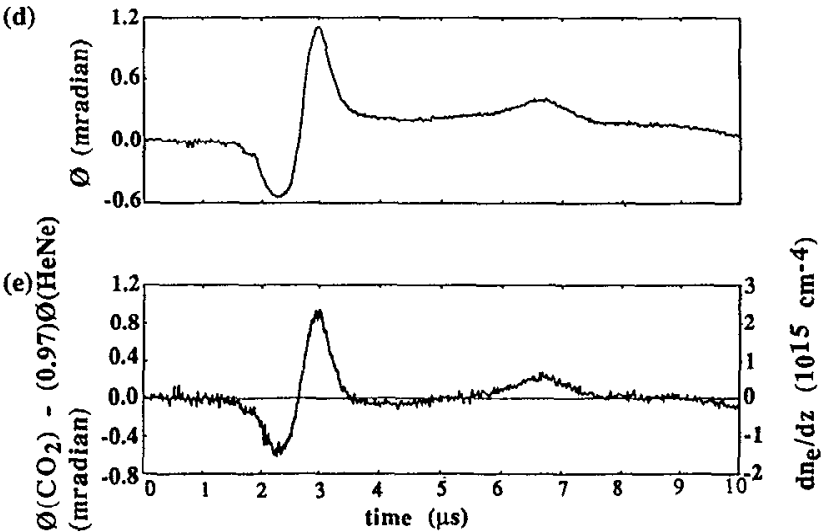

FIG. 3. Laser deflection data with lasers skimming the cathode. (a) Cathode voltage. (b) Anode current. (c) He-Ne deflection signal. (d) $\mathrm{CO}_{2}$ deflection signal. (e) $\mathrm{CO}_{2}$ deflection minus 0.97 times the $\mathrm{He}-\mathrm{Ne}$ deflection.

after shorting, showing the presence of plasma during the arc. On some shots, this feature was not observed, while other shots showed several plasma density gradient peaks during the arc.

At other locations within the diode, $\mathrm{CO}_{2}$ laser and $\mathrm{He}-\mathrm{Ne}$ laser deflection were performed on separate shots.

TABLE I. Parameters and minimum observable density gradients for this experiment.

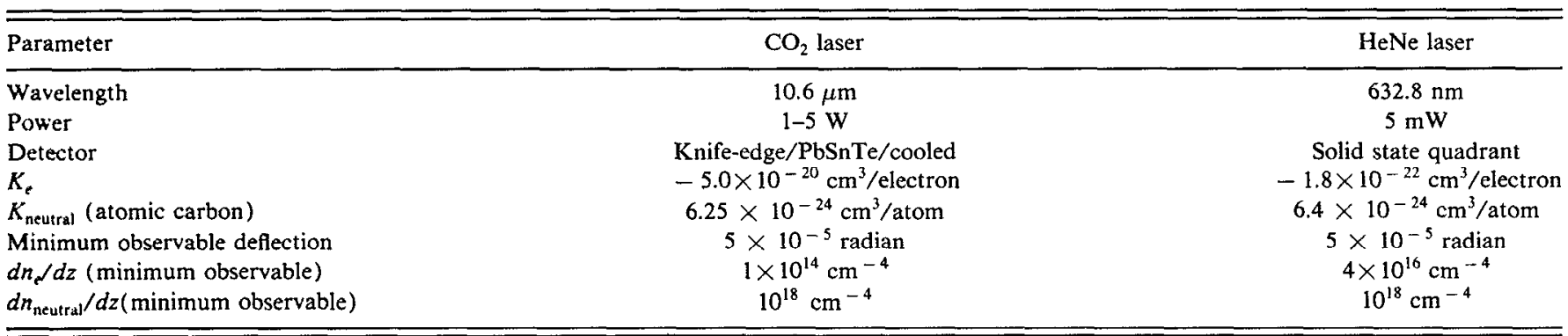


(a) $\mathrm{z}=1.5 \mathrm{~cm}$
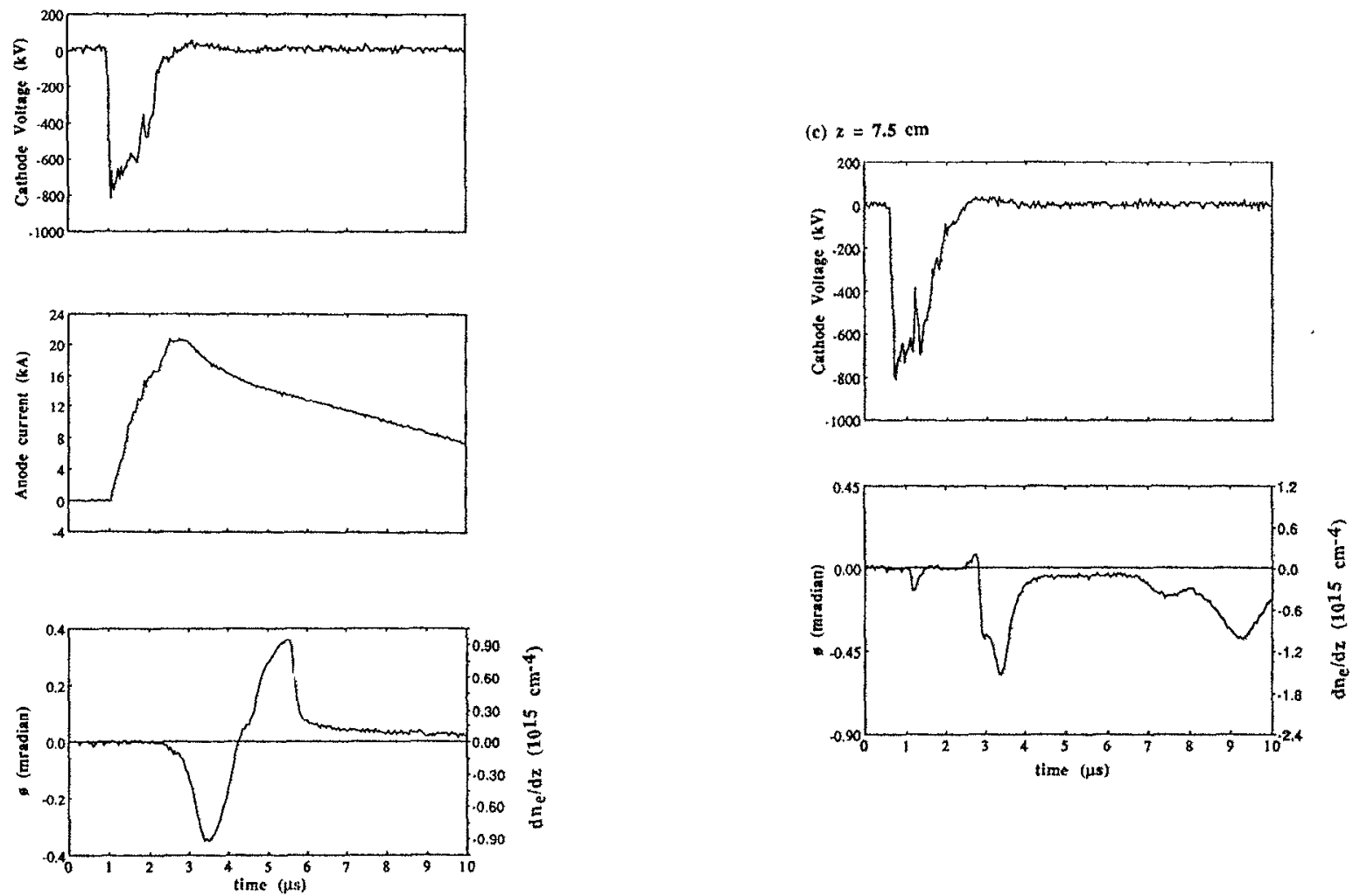

(b) $\mathrm{z}=4.5 \mathrm{~cm}$
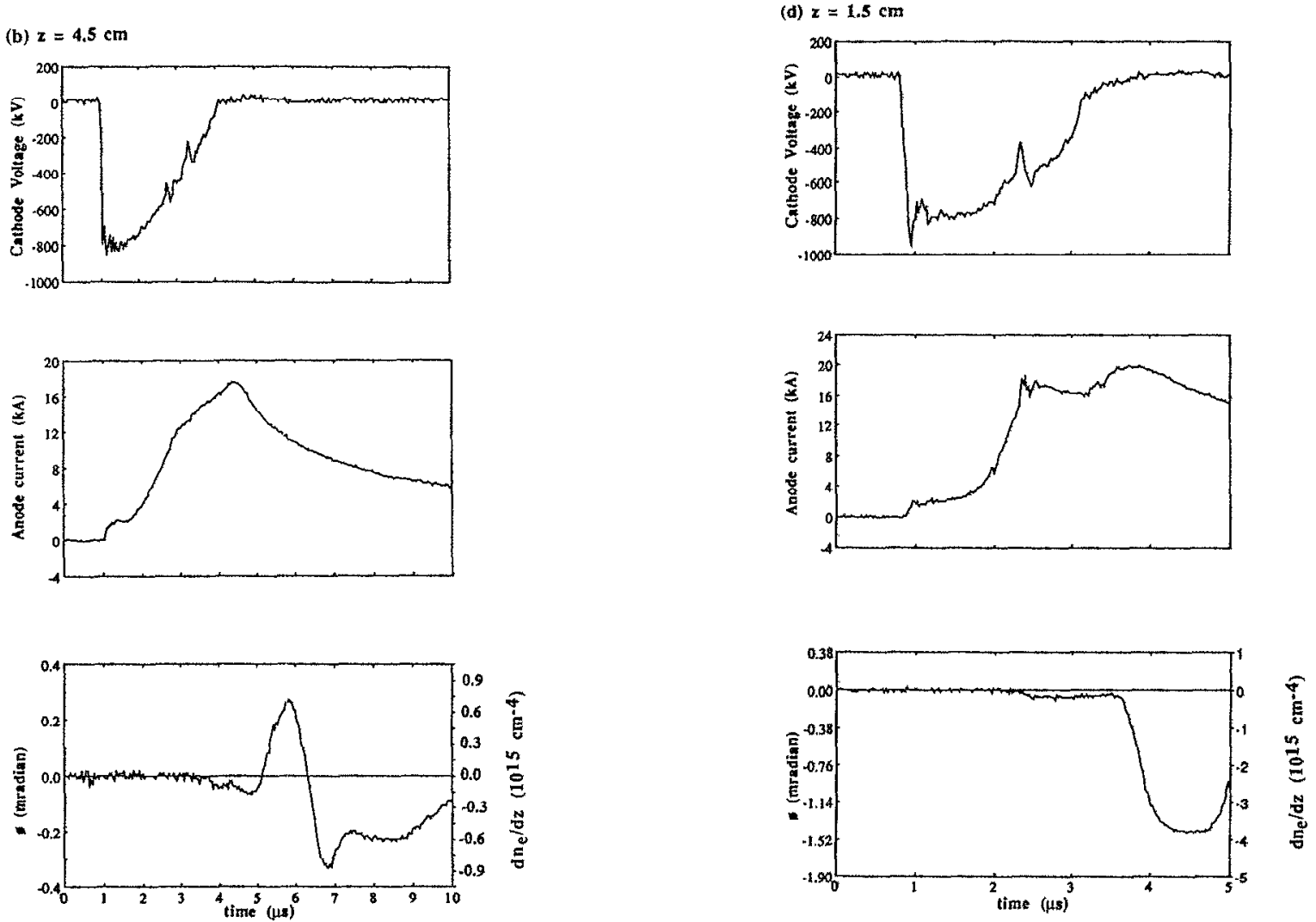

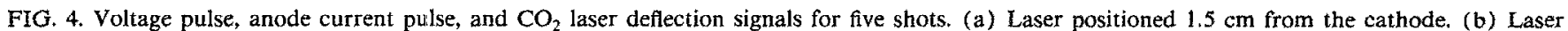

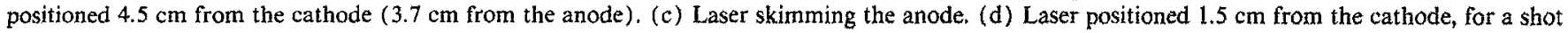

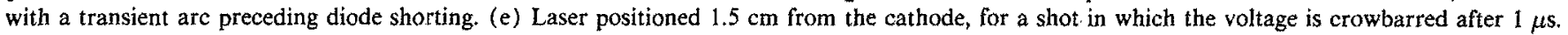



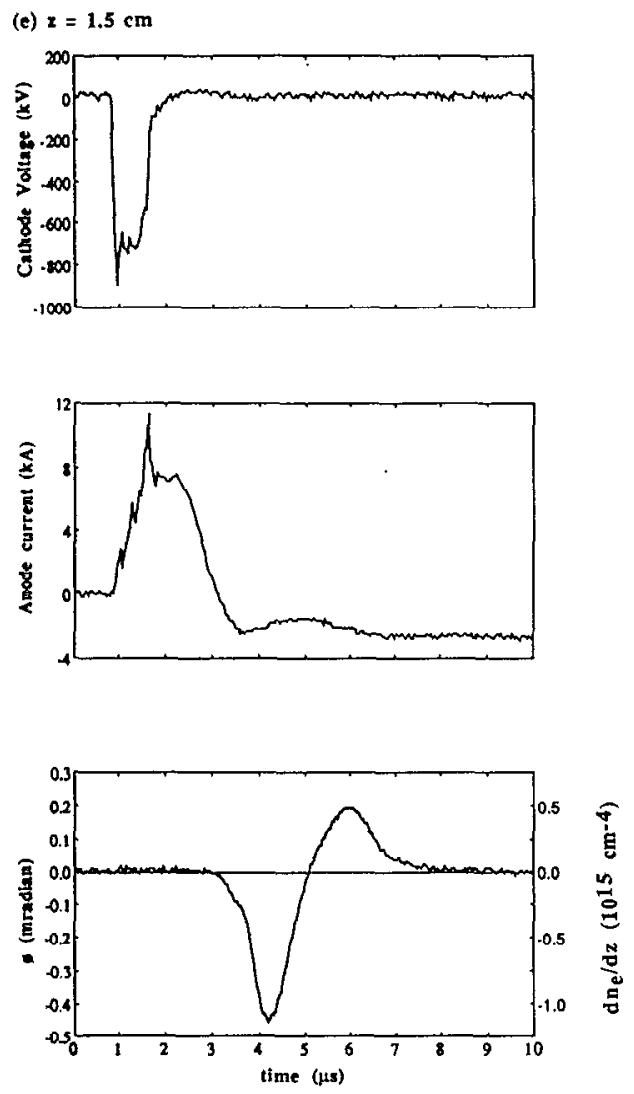

FIG. 4. (Continued).

The He-Ne deflection was not observable ( $<0.05 \mathrm{mrad})$ during the operating mode, indicating that the ncutral density gradient was less than $1 \times 10^{18} \mathrm{~cm}^{-4}$. Upon shorting, the He-Ne deflection increased over $\sim 1 \mu \mathrm{s}$, sometimes in an irregular fashion, and then gradually decreased over many microseconds. Near the cathode (anode), the neutral density increased in the direction of the cathode (anode). Shot-to-shot variability prevented a complete analysis of the post-shorting $\mathrm{CO}_{2}$ signals, for which both plasma and neutral gradients contribute. However, the contribution from the neutral density gradient following shorting could frequently be identified as a slowly decreasing deflection, upon which larger deflections from plasma gradients were superimposed. Because of the small (unobservable) neutral density gradient prior to shorting, the $\mathrm{CO}_{2}$ laser deflection observed prior to shorting is proportional to the plasma density gradient.

In Fig. 4, we show the $\mathrm{CO}_{2}$ laser deflection signals for several shots at various positions within the diode. Prior to shorting, the deflection is proportional to the plasma density gradient. A plasma density gradient of $2.6 \times 10^{15}$ $\mathrm{cm}^{-4}$ corresponds to a $1 \mathrm{mrad}$ deflection. After shorting, the majority of the deflection is attributable to the plasma density gradient, summed with a smaller slowly decreasing neutral density gradient signal. For deflections attributable to plasma gradients, a scale for $d n_{e} / d z$ is shown in Fig. 4 .

Figure $4(\mathrm{a})$ shows the $\mathrm{CO}_{2}$ laser deflection when the laser was positioned $1.5 \mathrm{~cm}$ from the cathode. A deflection from a cathode plasma density gradient of $\sim 1 \times 10^{14}$ $\mathrm{cm}^{-4}$ is observed prior to shorting, and develops into a bipolar plasma signal with peak plasma density gradients of $\sim 1 \times 10^{15} \mathrm{~cm}^{-4}$. Compared with the bipolar signal observed with the probe skimming the cathode, this signal has about one-half the magnitude, occurs 1-2 $\mu$ s later, and lasts nearly twice as long. Finally, a slowly-decaying neutral-produced gradient remains, with about one-fifth the magnitude observed skimming the cathode.

Figure 4(b) shows the $\mathrm{CO}_{2}$ deflection at a position 4.5 $\mathrm{cm}$ from the cathode $(3.7 \mathrm{~cm}$ from the anode). At this position near the center of the diode, several $\mathrm{cm}$ from cathode or anode, a deflection from a cathode plasma density gradient of $\sim 1 \times 10^{14} \mathrm{~cm}^{-4}$ was observed $0.5 \mu$ s prior to shorting. To our knowledge, this is the first detection of plasma during the operating mode of a relativistic electron beam diode several $\mathrm{cm}$ from either electrode.

In Fig. 4(c), we display a signal with the $\mathrm{CO}_{2}$ laser skimming the anode. When these data were taken, observations with the laser path blocked showed that negativegoing electrical noise signals were associated with transient arcs during the first $2 \mu$ s of the pulse. Consequently, the first negative-going voltage pulse on the laser deflection signal is likely to be noise. During the final $0.5 \mu$ s of the pulse, a plasma density gradient of $2 \times 10^{14} \mathrm{~cm}^{-4}$ is observed, with density increasing towards the anode. The anode surface energy deposition by accelerated electrons is expected to be $\sim 300 \mathrm{~J} / \mathrm{g}$ by this time. This is comparable to the absorbed dose of $330-500 \mathrm{~J} / \mathrm{g}$ required for the observation of anode plasma from a graphite anode in an earlier study of relativistic electron beam diodes. ${ }^{3}$ Consequently, the plasma density gradient may result from anode-produced plasma. Alternatively, the observed plasma deflection may result from cathode-produced plasma which has flowed to the anode and stagnated. Upon shorting, the deflection reverses, and after $1 \mu$ s, only a slowlydecreasing signal associated with anode-produced neutrals remains. Three microseconds later, plasma deflection signals are again observed.

In Fig. 4(d), we display a signal with the $\mathrm{CO}_{2}$ laser located $1.5 \mathrm{~cm}$ from the cathode, for a shot in which a transient arc precedes shorting. A cathode plasma density gradient of $2 \times 10^{14} \mathrm{~cm}^{-4}$ is apparent during and after the transient arc. This indicates the ability to examine plasma created during transient arcs. The large negative deflection signal for $t>4 \mu \mathrm{s}$ is clipped by the response of the knifeedge/detector system.

In Fig. 4(e), we display a signal with the $\mathrm{CO}_{2}$ laser located $1.5 \mathrm{~cm}$ from the cathode, for a shot in which the diode voltage is crowbarred at $1 \mu \mathrm{s}$. A pulse similar to the cathode plasma pulse of Fig. 4(a) is observed,but there is no persistent signal from a neutral density gradient. This is consistent with observations that neutral ablation is prevented by voltage crowbarring.

The data of Figs. 3 and 4 demonstrate the ability of $\mathrm{CO}_{2}$ laser deflection to detect cathode plasma throughout the diode during the operating mode. In conjunction with simultaneous He-Ne deflection observations, the post- 
shorting deflection signals, which include deflection from plasma and neutrals, may be interpreted.

\section{DISCUSSION}

Deflection of $\mathrm{He}-\mathrm{Ne}$ and $\mathrm{CO}_{2}$ laser beams by a relativistic electron beam diode allows measurement of plasma and neutral density gradients. The $\mathrm{He}-\mathrm{Ne}$ laser deflection is primarily a result of neutral density gradients of $\left(10^{18}\right.$ $\left.10^{19}\right) \mathrm{cm}^{-4}$. Prior to shorting, neutral density gradients are not observable $\left(<10^{18} \mathrm{~cm}^{-4}\right)$. The neutral gradients build up during the first microsecond after the diode shorts, and decay over many microseconds. Near the cathode (anode), the neutral density increases in the direction of the cathode (anode).

The $\mathrm{CO}_{2}$ laser deflection is largely a result of plasma density gradients of $\left(10^{14}-10^{15}\right) \mathrm{cm}^{-4}$ during the final microsecond preceding diode shorting, and during the subsequent arc. Near the cathode (anode), the plasma density prior to shorting increases in the direction of the cathode (anode). Near the middle of the diode, plasma density increases in the direction of the cathode prior to shorting.

With $\mathrm{CO}_{2}$ laser deflection, plasma density gradients as small as $\sim 1 \times 10^{14} \mathrm{~cm}^{-4}$ can be observed throughout the diode. Thus, $\mathrm{CO}_{2}$ laser deflection is a promising plasma diagnostic for long-pulse relativistic electron beam diodes. The He-Ne laser deflection provides a diagnostic of neutral density gradients. When $\mathrm{CO}_{2}$ laser deflection is used in conjunction with He-Ne laser deflection, plasma and neu- tral density gradients may be determined prior to shorting and during the subsequent arc.

\section{ACKNOWLEDGMENT}

This work was sponsored by Los Alamos National Laboratory.

'L. A. Rosocha and K. B. Riepe, Fusion Tech. 11, 576 (1987).

${ }^{2}$ J. J. Ramirez and D. L. Cook, J. Appl. Phys. 51, 4602 (1980).

${ }^{3}$ R. K. Parker, R. E. Anderson, and C. V. Duncan, J. Appl. Phys. 45, 2463 (1974).

${ }^{4}$ D. W. Swain, S. A. Goldstein, L. P. Mix, J. G. Kelly, and G. R. Hadley, J. Appl. Phys. 48, 1085 (1977).

${ }^{5}$ D. D. Hinshelwood, IEEE Trans. Plasma Sci. PS-11, 188 (1983); see also D. D. Hinshelwood, Explosive emission cathode plasmas in intense relativistic electron beam diodes, Ph.D. thesis, Department of Physics, Massachusetts Institute of Technology, 1984.

${ }^{6} J$. G. Kelly and L. P. Mix, J. Appl. Phys. 46, 1084 (1975).

${ }^{7}$ D. J. Johnson, E. J. T. Burns, J. P. Quintenz, K. W. Bieg, A. V. Farnsworth, Jr., L. P. Mix, and M. A. Palmer, J. Appl. Phys. 52, 168 (1981).

${ }^{8}$ M. E. Cuneo, Characteristics of the time-evolution of a microsecond electron beam diode with anode effects, Ph.D. thesis, Department of Nuclear Engineering, The University of Michigan, 1989.

${ }^{9}$ R. M. Gilgenbach, L. D. Horton, R. F. Lucey, Jr., S. Bidwell, M. Cuneo. J. Miller, and L. Smutek, in Proceedings of the Sth IEEE Pulsed Power Conference, Arlington, VA, June 10-12, 1985, (IEEE, New York, 1985), p. 126.

${ }^{10} \mathrm{C}$. L. Enloe, R. M. Gilgenbach, and J. S. Meachum, Rev. Sci. Instrum. 58, 1597 (1987).

"W. C. Gardiner, Jr., Y. Hidaka, and T. Tanzawa, Combustion and Flame 40, 213 (1981). 